\title{
Effect of inclination angle on the condensation of R134a inside inclined smooth tube
}

\author{
S. M. A. Noori Rahim Abadi*, Josua P. Meyer, J. Dirker \\ Department of Mechanical and Aeronautical Engineering, University of Pretoria, \\ Pretoria, South Africa
}

${ }^{*}$ Corresponding author. Tel.: +27 728035548

E-mail address: ali.abadi@up.ac.za

\section{Highlights}

- The inclination effect on void fraction is negligible at high mass fluxes.

- The inclination effect on void fraction is negligible at high vapour qualities.

- The inclination effect on pressure drop is negligible at high vapour qualities.

- Pressure drop increases as the void fraction increases. 


\begin{abstract}
Almost all work on condensation in tubes were conducted for smooth tubes in a horizontal or vertical orientation, and little has been done at other inclination angles. Recent experimental works with condensation at different inclination angles showed that the pressure drops were a function of inclination angle. It was therefore the purpose of this paper to numerically investigate the pressure drop of condensation inside a smooth tube at different inclination angles, and to give additional perspectives and insight to previous experimental works. The case study investigated was a smooth tube with an inner diameter of $8.38 \mathrm{~mm}$ and a length of $1488 \mathrm{~mm}$. The condensing fluid was R134a and the saturation temperature was $40^{\circ} \mathrm{C}$. Simulations were conducted at a heat flux of approximately $5 \mathrm{~kW} / \mathrm{m}^{2}$, at mass fluxes of $100-600 \mathrm{~kg} / \mathrm{m}^{2} . \mathrm{s}$, and the inclination angles were varied from vertical downward to vertical upward. The Volume of Fluid (VOF) multiphase flow formulation was used and ANSYS FLUENT was used as solver of the governing equations. The predicted results showed a good agreement with experimental data. It was found that the effect of inclination angle on pressure drop and void fraction became negligible at high mass fluxes and vapour qualities. The pressure drop increased as the void fraction increased. The pressure drops also increased when the mass fluxes increased. These increases were more significant at high vapour qualities.
\end{abstract}

Keywords: Condensation, inclined smooth tube, pressure drop, void fraction, VOF. 


\section{Introduction}

Many systems make use of vapour-compression cycles. The condenser in the vapour compression system needs to reject heat by condensing the working fluid from a gas to a liquid. Applications of vapour-compression cycles are found in the air-conditioning and refrigeration industries, oil refineries, petrochemical and chemical processing plants, and natural gas processing plants (Fair, 1960; Liebenberg and Meyer, 2008a, b). Other applications of condensation occur in nuclear, coal fired, and concentrated solar power generation plants where steam is condensed in air and water-cooled cooling towers. In the majority of these cases condensation occurs in tubes which are configured horizontally.

In recent studies by Meyer and co-workers (Lips and Meyer, 2012a, b, c, d), an increase in heat transfer of up to $20 \%$ at an inclination of $-15^{\circ}$ (downward flow) was observed for combinations of low mass fluxes and vapour qualities. The pressure drops at these inclination angles were also lower than at horizontal angles. In upward flow inclination angles the heat transfer decreased. At higher mass fluxes and vapour quality conditions in which the shear forces were dominant the flow patterns were mainly annular with the heat transfer coefficients independent of the tube inclination angle. In addition, the observed flow patterns did not correlate well with theoretical models.

Olivier et al. (2016) investigated the effect of the inclination angle on the pressure drop and void fraction inside a smooth tube. They found that the inclination angles did not affect the void fractions and heat transfer coefficients at high mass fluxes and vapour qualities. However, a significant increase in heat transfer coefficients occurred at low mass fluxes and low qualities.

It was also found that void fraction and flow pattern map predictions were found to be inadequate for inclined flow conditions and gravity effects must be taken into consideration (Lips and Meyer, 2011, 2012a). Meyer et al. (2014) studied the effect of saturation temperature on the heat transfer coefficient inside an inclined tube. They considered the entire range of inclination angles from $-90^{\circ}$ downward, to $+90^{\circ}$ upward. Results showed that heat transfer coefficients increased with mass flux, and mean vapour quality. Also, that the effect of inclination was more pronounced at low mass flux, low 
mean vapour qualities, and at a high saturation temperature. Furthermore, they observed that the heat transfer coefficients reduced irrespective of the inclination angles and mass fluxes. It was due to the fact that at higher saturation temperatures, lower heat transfer coefficients corresponded to lower pressure drops.

Del Col et al. (2014) studied the condensation phenomenon inside an inclined square cross-section mini channel with a hydraulic diameter of $1.32 \mathrm{~mm}$. They used two refrigerants, $\mathrm{R} 134 \mathrm{a}$ and $\mathrm{R} 32$, and the saturation temperature was $40^{\circ} \mathrm{C}$ during their experiments. They found that the orientation of the channel had a negligible effect on condensation for downward flow at high mass fluxes, and minor effects for flow in the upward direction. However, at lower mass fluxes the effects were significant, and specifically at qualities lower than $60 \%$. The authors also developed a method to predict at which mass flux, critical mass flux, the channel inclination affected the condensation heat transfer by using the Buckingham theorem. In fact, at mass fluxes lower than the critical one, depending on the channel inclination angle and type of the refrigerant, the condensation heat transfer coefficient may dramatically decrease as compared to that in horizontal configuration. As an example, their proposed method confirmed that the effect of the inclination angle during downward flow of R32 in their test geometry started at the mass flux lower than $G=200 \mathrm{~kg} / \mathrm{m}^{2} \mathrm{~s}$.

Xing et al. (2015) investigated condensation heat transfer at different inclination angles of refrigerant R245fa in a smooth tube with a diameter of $14.8 \mathrm{~mm}$ and length of $1.2 \mathrm{~m}$. The results showed that the maximum heat transfer coefficient and minimum pressure drop occurred at inclination angles of $30^{\circ}$ and $15^{\circ}$, and the results were very sensitive to inclination angles near the horizontal position. They observed that the main flow patterns in the condenser tube were stratified-smooth flow, stratified-wavy flow, and intermittent flow. They also developed a new correlation of condensation heat transfer coefficients using a non-dimensional parameter analysis.

The effect of the inclination angle in the presence of non-condensable gases have also been investigated (Caruso et al., 2012, 2013a). Caruso and Mio (2014) investigated steam condensation in the presence of non-condensable gases within horizontal and inclined tubes theoretically and experimentally. The results showed that the presence of non- 
condensable gases adversely affected the heat transfer coefficients. They also presented a correlation based on dimensionless numbers which was compared with literature.

It can in general be concluded that little work had been done on condensation at different inclination angles as confirmed by a review article by Lips and Meyer (2011). Subsequent work on this topic mainly focused on the experimental (Caruso et al., 2013b; Chato, 1962; Beggs and Brill, 1973; Dziubinski et al., 1995) and analytical aspects (Lips and Meyer, 2012a; Szijártó et al., 2014; Lizarraga-Garcia et al., 2016) with many simplifying assumptions. Computational Fluid Dynamics (CFD) of the condensation phenomenon inside an inclined tube can explain the flow characteristics inside the tube cheaper and quicker than experimental work. Previous CFD works mainly focused on numerical simulations of condensation inside horizontal or vertical smooth tubes (Behafarid et al., 2015; Azizi and Ahmadloo, 2016; Fu et al., 2016; Li, 2013; Lin and Wang, 2013; Ratkovich et al., 2013; Ndinisa et al., 2005).

It was therefore the purpose of this study to numerically investigate the effect of inclination angles on pressure drops and void fractions. This work also supplements the previous experimental works (Lips and Meyer, 2011,2012b , c) conducted by some of the authors of this paper.

\section{Governing equations}

\subsection{Assumptions}

The governing equations used were the equations of conservation of mass, momentum, and energy. The relevant assumptions made in supplementation to these governing equations for this study were:

1. The flow was unsteady, three-dimensional and turbulent.

2. The working fluid properties were constant at the saturation temperature considered.

3. The mass transfer between liquid and vapour phases took place at saturation temperature.

4. As the the Volume of Fluid (VOF) method was used for the simulation, the velocity difference between phases were neglected.

5. Both phases were incompressible Newtonian fluids, Ma $<<0.3$, (Städtke, 2006). 
6. Three-dimensional CFD simulations were performed without any limiting assumption for the entrance effect.

\subsection{Volume of Fluid Model}

In the VOF model, the volume fractions of each of the two phases in a computational cell sums to unity:

$\alpha_{l}+\alpha_{v}=1$

Where, $\alpha$, is the volume fraction and, $l$, and, $v$, denotes the liquid and vapour phases.

The continuity equations for the volume fractions of each phase are:

$$
\begin{aligned}
& \frac{\partial \alpha_{v}}{\partial t}+\nabla \cdot\left(\vec{u} \alpha_{v}\right)=\frac{S_{v}}{\rho_{v}} \\
& \frac{\partial \alpha_{l}}{\partial t}+\nabla \cdot\left(\vec{u} \alpha_{l}\right)=\frac{S_{l}}{\rho_{l}}
\end{aligned}
$$

Where, $u$, and, $t$, are velocity and time respectively. $S$, is the source term due to phase change.

In the VOF method only one momentum and energy equation are solved for the mixture:

$$
\begin{aligned}
& \frac{\partial\left(\rho_{m} \vec{u}\right)}{\partial t}+\nabla \cdot\left(\rho_{m} \vec{u} \vec{u}\right)=-\nabla p+\nabla \cdot\left[\mu_{m, e f f}\left(\nabla \vec{u}+(\nabla \vec{u})^{T}\right)\right]+\rho_{m} \vec{g}+\vec{F}_{\sigma} \\
& \frac{\partial\left(\rho_{m} E\right)}{\partial t}+\nabla \cdot\left[\vec{u}\left(\rho_{m} E+p\right)\right]=\nabla \cdot\left(k_{m, e f f} \nabla T\right)+S_{E}
\end{aligned}
$$

Where $\rho, p, g$ and, $F_{\sigma}$, are density, pressure, gravitational acceleration and the surface tension force. Furthermore $E, T, k$, and $S_{E}$ are the internal energy, temperature, thermal conductivity and energy source term due to the condensation.

In the VOF method the average phase properties are 
$k_{m}=\alpha_{l} k_{l}+\alpha_{v} k_{v}$

$\rho_{m}=\alpha_{l} \rho_{l}+\alpha_{v} \rho_{v}$

$\mu_{m}=\alpha_{l} \mu_{l}+\alpha_{v} \mu_{v}$

The effective parameters, $\mu_{\text {eff, }}$ and, $k_{\text {eff, }}$ are defined as:

$\mu_{\text {eff }}=\mu_{L}+\mu_{t}$

$k_{\text {eff }}=k_{L}+k_{t}$

Where, $k_{t}$, and, $\mu_{t}$, are the turbulent thermal conductivity and the viscosity.

In this study the effect of surface tension force was taken into account using the continuum surface force, as proposed by Brackbill et al. (1992). The resulting source term due to surface tension is added to the momentum equation to capture the liquid hold-up and two-phase interface correctly. The source term is defined as:

$$
F_{\sigma}=\sigma \frac{\alpha_{l} \rho_{l} k_{v} \nabla \alpha_{v}+\alpha_{v} \rho_{v} k_{l} \nabla \alpha_{l}}{\frac{1}{2}\left(\rho_{v}+\rho_{l}\right)}
$$

Where $\sigma$, is the surface tension. The curvatures of the liquid and vapour phases were accommodated as:

$k_{l}=\nabla \cdot \frac{\nabla \alpha_{l}}{\left|\nabla \alpha_{l}\right|}, \quad k_{v}=\nabla \cdot \frac{\nabla \alpha_{v}}{\left|\nabla \alpha_{v}\right|}$

\subsection{Turbulence modelling}

In this study the two-equation turbulence model, $k-\varepsilon$, was implemented, which its suitable performance for in-tube condensation has been previously approved (Li, 2013). The equations of turbulence energy and dissipation rate are represented as follows (Yang and Shih, 1993): 


$$
\begin{aligned}
\frac{\partial\left(\rho_{m} k\right)}{\partial t}+\nabla \cdot\left(\rho_{m} \vec{u} k\right) & =\nabla \cdot\left[\left(\mu_{L, m}+\frac{\mu_{\mathrm{t}, m}}{\sigma_{k}}\right) \nabla k\right]+\left[\mu_{t, m}\left(\nabla \vec{u}+(\nabla \vec{u})^{T}\right): \nabla \cdot \vec{u}\right]-\rho_{m} \varepsilon+G_{b} \\
\frac{\partial\left(\rho_{m} \varepsilon\right)}{\partial t}+\nabla \cdot\left(\rho_{m} \vec{u} \varepsilon\right) & =\nabla \cdot\left[\left(\mu_{L, m}+\frac{\mu_{\mathrm{t}, m}}{\sigma_{\varepsilon}}\right) \nabla \varepsilon\right] \\
& +\frac{\varepsilon}{k}\left(C_{1 \varepsilon}\left[\mu_{t, m}\left(\nabla \vec{u}+(\nabla \vec{u})^{T}\right): \nabla \cdot \vec{u}\right]-C_{2 \varepsilon} \rho_{m} \varepsilon\right)+\mathrm{C}_{1 \varepsilon} \mathrm{C}_{3 \varepsilon} \frac{\varepsilon}{k} G_{b}
\end{aligned}
$$

Where $k$ and $\varepsilon$ are turbulent kinetic energy and turbulent energy dissipation rate respectively. The parameter $G_{b}$ is the generation of turbulence kinetic energy due to buoyancy. The turbulent viscosity, $\mu_{t}$, relates to turbulence energy, $k$, and dissipation rate, $\varepsilon$, such that:

$$
\mu_{t, \mathrm{~m}}=C_{\mu} \frac{\rho_{m} k^{2}}{\varepsilon}
$$

The constants in the above-mentioned model are defined as:

$$
C_{\mu}=0.09, C_{1 \varepsilon}=1.44, C_{2 \varepsilon}=1.92, C_{3 \varepsilon}=\tanh \left|\frac{v}{u}\right|, \sigma_{k}=1.0, \sigma_{\varepsilon}=1.3
$$

Further details on the constants and parameters can be found in (Yang and Shih, 1993).

\subsection{Phase change source terms}

In this study the effect of phase change phenomenon was considered via source terms in the governing equations. The condensation source terms were (Lee, 1980; Liu et al., 2012):

$$
\begin{aligned}
& S_{l}=r_{l} \alpha_{l} \rho_{l} \frac{T-T_{\text {sat }}}{T_{\text {sat }}} \quad T \geq T_{\text {sat }} \\
& S_{v}=r_{v} \alpha_{v} \rho_{v} \frac{T_{\text {sat }}-T}{T_{\text {sat }}} \quad T<T_{\text {sat }}
\end{aligned}
$$


Where, $T_{\text {sat, }}$, is the saturation temperature of the working fluid. The coefficients, $r_{v}$, and, $r$, was tuned to fit the experimental data. Excessively small values of the coefficient, $r$, lead to a significant deviation between the interfacial and saturation temperature. However, too large values of, $r$, caused numerical convergence challenges. The values of, $r_{v}$, and, $r$, were both $5500 \mathrm{~s}^{-1}$ (Lee, 1979).

The relevant source term in the energy equation is defined as follows:

$$
S_{E}=S_{l} h_{l v}
$$

Where, $h_{l v}$, is the latent heat of condensation. The aforementioned source terms in mass, momentum and energy equations were implemented in the ANSYS FLUENT 17.1 software as a "User Defined Function".

The average heat transfer coefficients along the tube length were calculated as follows:

$$
h_{\text {ave }}=\frac{q^{\prime \prime}}{T_{\text {sat }}-T_{\text {wall,ave }}}
$$

Where $T_{\text {wall,ave }}$ and $q$ " are the average tube wall temperature and heat flux respectively.

\subsection{Boundary conditions and solution method}

The computational domain of the present numerical investigation is illustrated in Fig. 1. The computational domain modelled a circular smooth tube with an inner diameter of $8.38 \mathrm{~mm}$ and a length of $1.488 \mathrm{~m}$. The following boundary conditions were assumed:

1. At the tube inlet the mass fluxes of the vapour and liquid phases, and mixture temperature were given.

2. At the outlet section a static gauge pressure of $0 \mathrm{~Pa}$ was specified.

3. A constant heat flux $5105 \mathrm{~W} / \mathrm{m}^{2}$ was prescribed as boundary condition on the tube inner wall as all experiments were conducted with a constant heat transfer rate of $200 \mathrm{~W}$ over the test section. Although the heat flux was not constant during experiments the tube length was relatively short and only the average heat transfer coefficients of the test section lengths were reported (Lips and Meyer, 


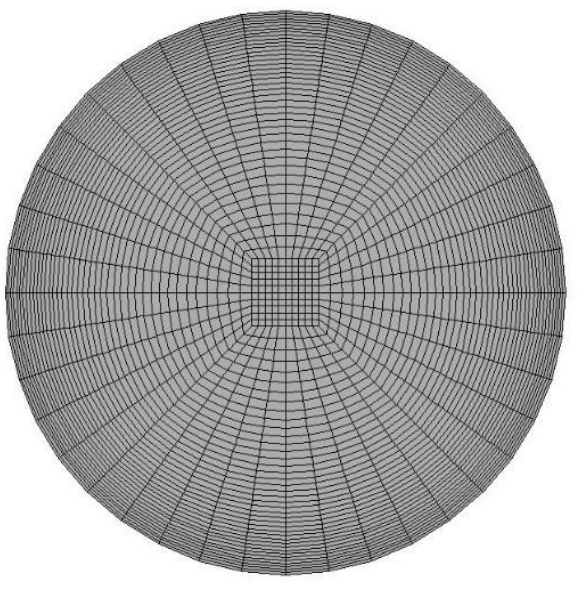

(a)

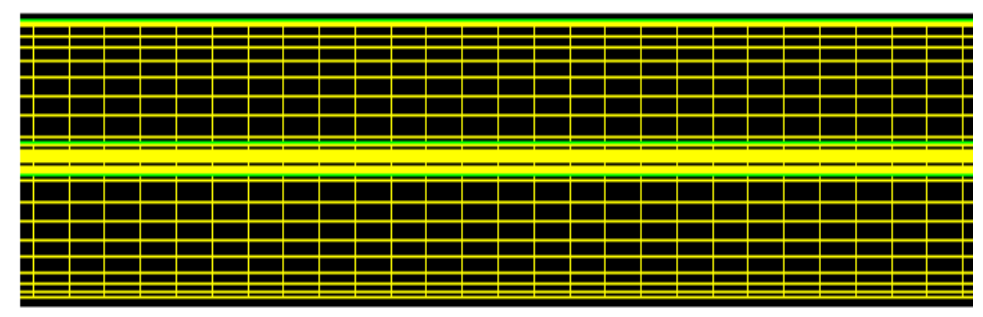

(b)

Fig. 1 Schematic of the computational domain; (a) tube cross section, (b) axial tube direction (not to scale). 
2011, 2012b, c; Meyer et al., 2014; Olivier et al., 2016). The verification results in Sec. 3.1, shows that this assumption is justifiable.

4. A no slip condition were assumed at the tube wall.

5. It was assumed that the vapour phase filled the tube at the saturation temperature of $40^{\circ} \mathrm{C}$, at the beginning of the simulation.

6. The contact angle between the liquid and solid at the saturation temperature of $40^{\circ} \mathrm{C}$, was set to $5.8^{\circ}$ (Vadgama and Harris, 2007).

The ANSYS FLUENT 17.1 commercial software package was used as the numerical solver of the governing equations. The SIMPLE method was used for the pressure-velocity coupling. The second order upwind method was utilized for the discretization. To capture the liquid/vapour interphase the Geo-Reconstruction scheme (Rudman, 1997) was utilized. The convergence criterion was set to $10^{-5}$ for the residual of each parameter. A time step size of $10^{-4} \mathrm{~s}$ was used for the simulations.

All the presented results are at the time of $t=600 \mathrm{~s}$, in which the variations of all parameters are less than $4 \%$. Such conclusion was approved and reported by the previously experimentations of the authors (Lips and Meyer, 2011, 2012b, c).

\section{Experimental data}

The schematic of the experimental rig is given in Fig. 2. The test section was constructed in the configuration of a tube-in-tube counter-flow heat exchanger, with water flowing in the annulus and the refrigerant through the test section. Condensation therefore occurred in the inner tube. The test section inner tube diameter was $8.38 \mathrm{~mm}$, and its length was $1488 \mathrm{~mm}$. At the outlet of the tube the flow regimes were captured with a video camera. The inclination angle of the test section could be changed to different inclination angles over a range from $-90^{\circ}$ vertical downward, to $+90^{\circ}$ vertical upward; with $0^{\circ}$ presenting a horizontal angle.

The heat transfer rates during condensation were determined by measuring the mass flow rate through the annulus and the temperature increase from the annulus inlet to annulus outlet. The heat transfer coefficients were determined from the heat flux in the annulus, and measurements of the average wall temperature of the refrigerant inlet- and 


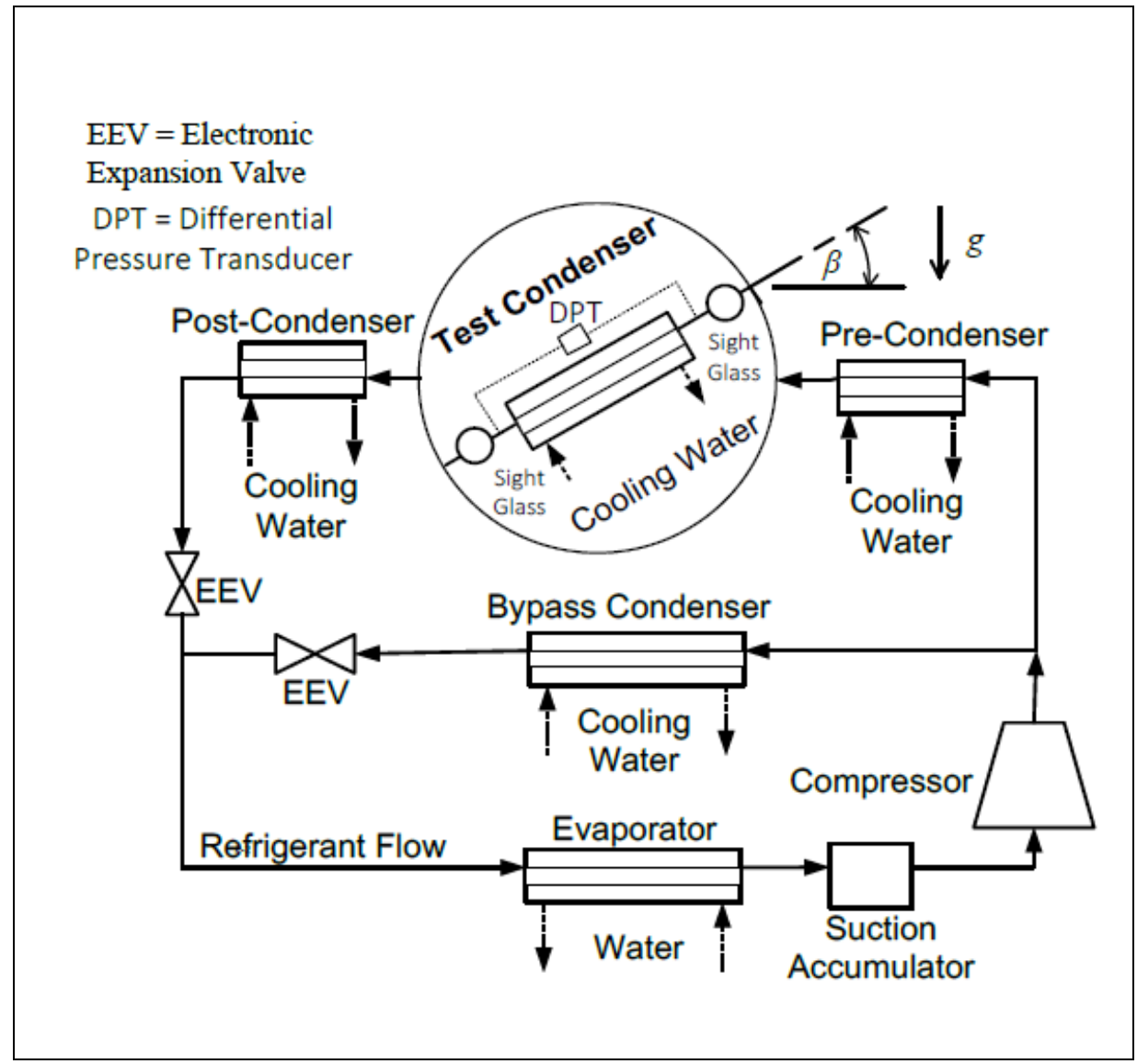

Fig. 2 Schematic of the experimental set-up that was used in the experimental study of Lips and Meyer (2012c). 
outlet temperatures. The heat transfer coefficients were therefore the average heat transfer coefficients over the test section lengths. The uncertainties of these average heat transfer coefficients were $\pm 10 \%$.

The inlet and outlet quality of the test section were determined from an energy balance using water cooled pre- and post-condensers, with detail available in (Lips and Meyer, $2011,2012 b, c)$. The heat transfer coefficients were determined for mass fluxes of 100 to $400 \mathrm{~kg} / \mathrm{m}^{2} . \mathrm{s}$, at saturation temperatures of 30,40 and $50{ }^{\circ} \mathrm{C}$, at different qualities and different inclination angles. During experiments the heat transfer rate of condensation was kept constant at $200 \mathrm{~W}$, by controlling the mass flow rates and water inlet temperature through the annulus with a thermal bath.

As only the heat transfer rate of $200 \mathrm{~W}$, and the average heat transfer coefficients (from the average temperature measurements) over the test section length were determined, the local heat fluxes were not determined. As the tube length was relatively short, a constant heat flux during condensation of $5105 \mathrm{~W} / \mathrm{m}^{2}$ was assumed for this study for the numerical simulations.

\section{Results and discussion}

In this paper simulations were conducted at the same operating conditions than previous experimental studies (Lips and Meyer, 2011, 2012b, c). The mass fluxes considered were from $100-600 \mathrm{~kg} / \mathrm{m}^{2} . \mathrm{s}$, qualities of $10-90 \%$, a saturation temperature of $40^{\circ} \mathrm{C}$, and inclination angles from $-90^{\circ}$ (vertical downward flow) to $+90^{\circ}$ (vertical upward flow). For horizontal flow the inclination angle was defined to be $0^{\circ}$. It is also worth mentioning that the minimum Reynolds numbers for the liquid and vapour phases, which corresponds to $G=100 \mathrm{~kg} / \mathrm{m}^{2} . \mathrm{s}$, were 5143 (Uliquid $=0.08 \mathrm{~m} / \mathrm{s}$ ) and $66773\left(\right.$ u $_{\text {vapour }}=2 \mathrm{~m} / \mathrm{s}$ ) respectively, hence it confirmed that the flow field was turbulent.

Simulations were considered on different grids sizes to ensure a grid independent solution. The grid independency checks were conducted at the full range of inclination angles from $-90^{\circ}$ to $+90^{\circ}$, at a quality of $50 \%$ and a mass flux of $100 \mathrm{~kg} / \mathrm{m}^{2}$.s (Fig. 3a), as well as for a quality of $25 \%$ and a mass flux of $300 \mathrm{~kg} / \mathrm{m}^{2} . \mathrm{s}$ (Fig $3 \mathrm{~b}$ ). In the grid dependence study the variations in velocities, temperatures, pressures, heat transfer 


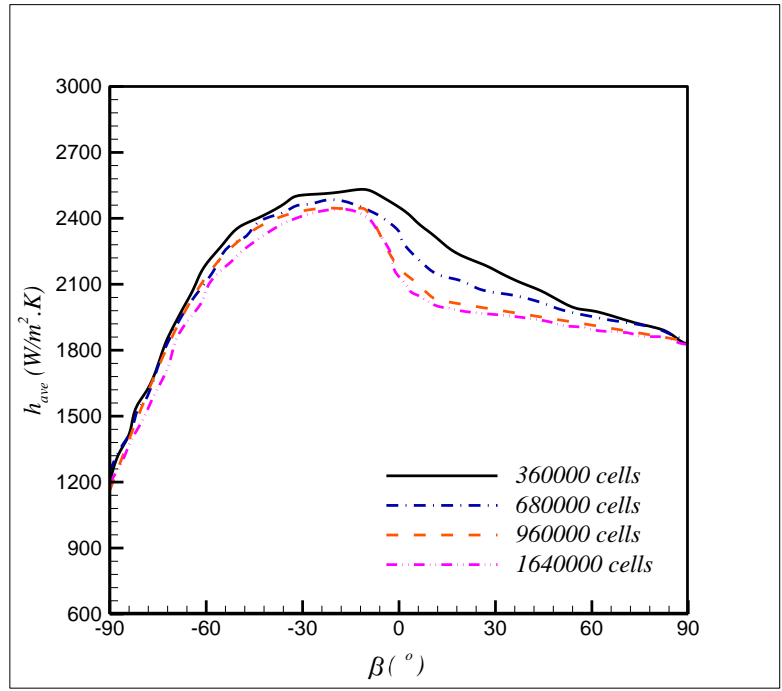

(a)

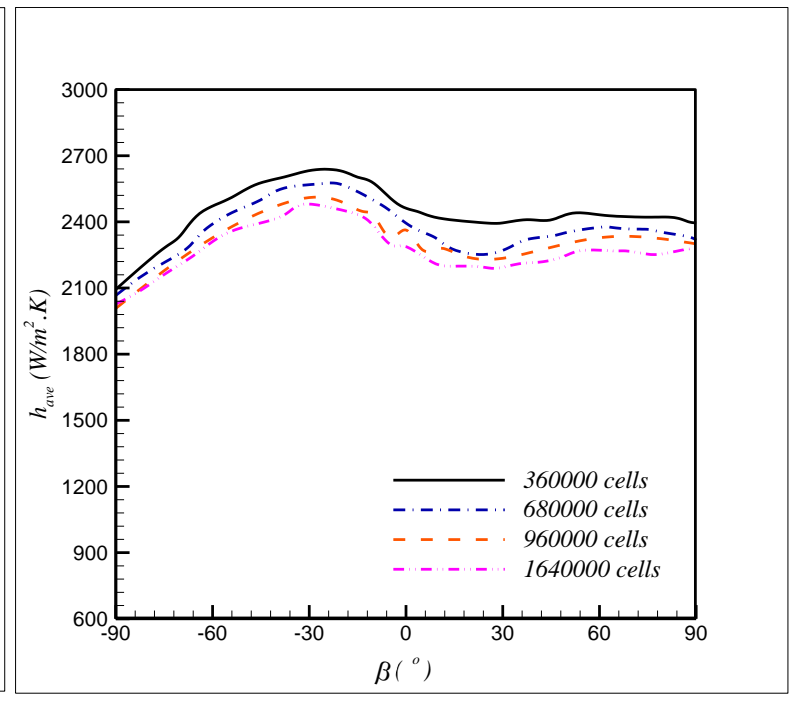

(b)

Fig. 3 Grid independent analysis of simulated heat transfer coefficient as function of inclination angles for different grid sizes at: (a) a quality of $50 \%$ and a mass flux of $100 \mathrm{~kg} / \mathrm{m}^{2}$.s , and (b) a quality of $25 \%$ and a mass flux of $300 \mathrm{~kg} / \mathrm{m}^{2} . \mathrm{s}$. 
coefficients, etc., were considered. Although all these variables were monitored it has been found that although the results in general were grid dependant, the pressure drop values were not as sensitive to the grid size as compared to the other variables, such as specifically the heat transfer coefficients (or temperatures). For this reason the effect of grid size on the variations of the pressure drops were not reported in this study, but rather the heat transfer coefficients.

Fig. 3 shows the variations of the heat transfer coefficient as function of different inclination angles for different grid sizes. Four different grid sizes were considered from 360000 to 1640000 cells. It was found that the results of the simulations for the grids of 960000 and 1640000 cells were negligible. Therefore, the grid with 960000 cells was utilized for all the simulation cases in this study.

\subsection{Pressure drops}

Fig. 4 shows the numerically simulated apparent pressure drops and measured apparent pressure drops by Lips and Meyer (2012c) at different inclination angles, for mass fluxes of $200 \mathrm{~kg} / \mathrm{m}^{2} . \mathrm{s}, 300 \mathrm{~kg} / \mathrm{m}^{2} . \mathrm{s}$, and $400 \mathrm{~kg} / \mathrm{m}^{2} . \mathrm{s}$. The apparent pressure drop was defined as the difference between the pressure drops in inclined and horizontal orientation (Lips and Meyer, 2012c). Each of these conditions are given for qualities of 25\% (Fig. 4a), 50\% (Fig. 4b), and 75\% (Fig. 4c). Although the apparent pressure drops in this study were also considered at mass fluxes of $500 \mathrm{~kg} / \mathrm{m}^{2} . \mathrm{s}$, and $600 \mathrm{~kg} / \mathrm{m}^{2} . \mathrm{s}$, the details are not reported here as it was found that the trends and flow regimes were similar to a mass flux of $400 \mathrm{~kg} / \mathrm{m}^{2} . \mathrm{s}$.

In general, the numerical results in Fig. 4, compared well with the experimental data and as can be expected the apparent pressure drop increased as the inclination angle increased from vertical downward flow $\left(\beta=-90^{\circ}\right)$ to vertical upward flow $\left(\beta=+90^{\circ}\right)$. However, for the higher mass fluxes of $400 \mathrm{~kg} / \mathrm{m}^{2} . \mathrm{s}$, the agreement is not as good as for the simulations at lower mass fluxes of $200 \mathrm{~kg} / \mathrm{m}^{2}$.s. However, the deviations are small. However, in general a good agreement exists and 93\% of the numerical simulations fall within the uncertainties of the measurements, which were $4 \%$. Furthermore, $7 \%$ of the numerical simulations differed to within $18 \%$ of the experimental data. 


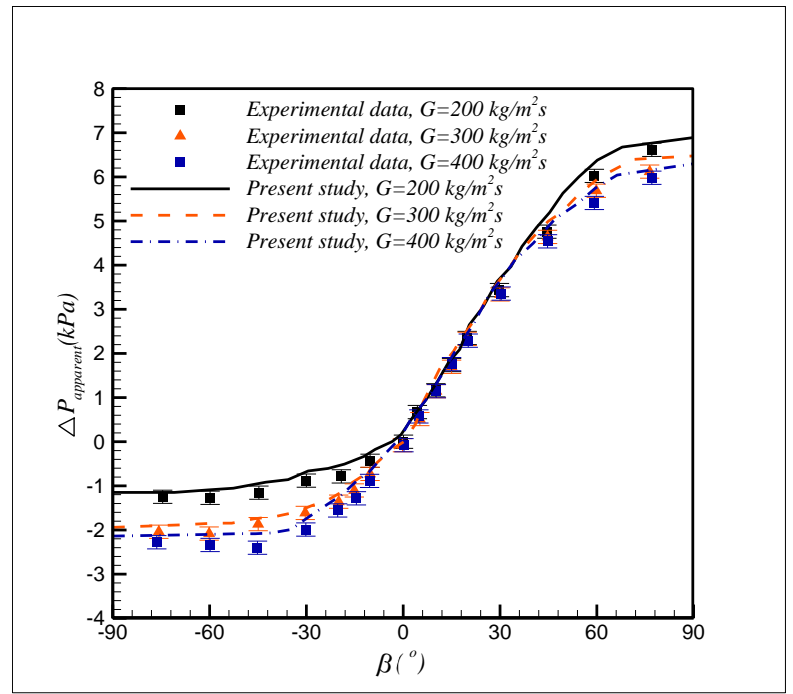

(a)

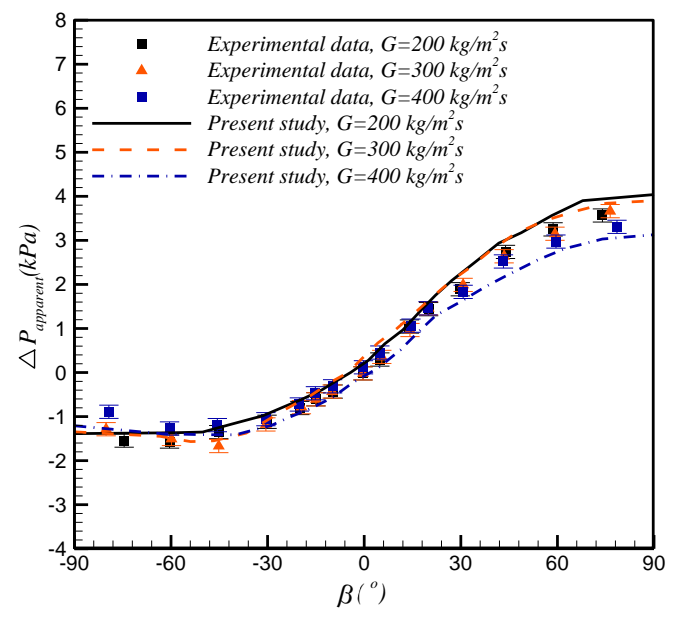

(b)

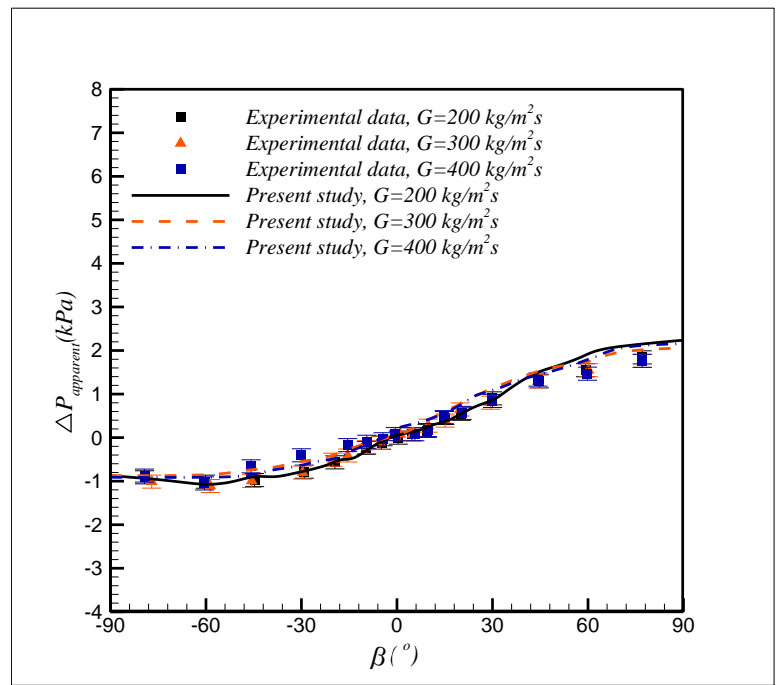

(c)

Fig. 4 Simulated and measured apparent pressure drops as function of inclination angles and mass fluxes for qualities of: (a) $x m=0.25$, (b) $x m=0.50$, and (c) $x m=0.75$. 
In general, for downward flows $\left(-90^{\circ}<\beta<0^{\circ}\right)$, the apparent pressure drops decreases due to the effect of gravity which acts in the opposite direction when the orientation gradually tends to increase into a vertical upward direction. For upward flows, $\left(0^{\circ}<\right.$ $\beta<+90^{\circ}$ ), the results show that the inclination angle had a much more significant effect on the apparent pressure drops. This is due to the fact that the flow regime in an upward direction is mostly annular, therefore, the shear forces are much larger than the gravity forces. Furthermore, as the quality increases from Fig. 4a-c, the apparent pressure drop decreases significantly. This is due to the fact that larger values of vapour quality lead to a decrease of mixture density.

Fig. 5 shows the effect of mass flux and inclination angle on pressure drop. In general as can be expected the pressure drop increased as the mass flux increased. As discussed previously, due to the change of flow regimes from downward flow to upward flow the pressure drops increased significantly. The steep slope of the pressure drop as function of inclination angle, in the vicinity of the inclination angle of zero (horizontal case), supports this interpretation. For the mass flux of $100 \mathrm{~kg} / \mathrm{m}^{2} . \mathrm{s}$, the pressure drops are lower than zero, for $-90^{\circ}<\beta<+15^{\circ}$. The reason for this is that at low mass fluxes for downward flow, the gravity forces are larger than the shear forces, which caused the increase in pressure drops.

Fig. 6 illustrates the pressure drop as function of quality and mass flux for a horizontal tube $\left(\beta=0^{\circ}\right)$. The pressure drop increased with an increase in mass flux and vapour quality due to increase of the shearing force and consequently the frictional pressure drop. The effect of vapour quality on the pressure drop is more significant at higher values of mass flux. It is due to the fact that at the higher mass fluxes and vapour qualities the shear forces are much higher than the gravity forces. This is also confirmed in Figs. 3 and 5, which shows that high inclination angles have no significant effect on either the heat transfer coefficients or pressure drops. This deduction can also be attributed to the flow regimes, which confirmed that the flow regime becomes annular at higher values of vapour quality and mass flux, in which the shear forces are dominant if compared to the gravity forces. 


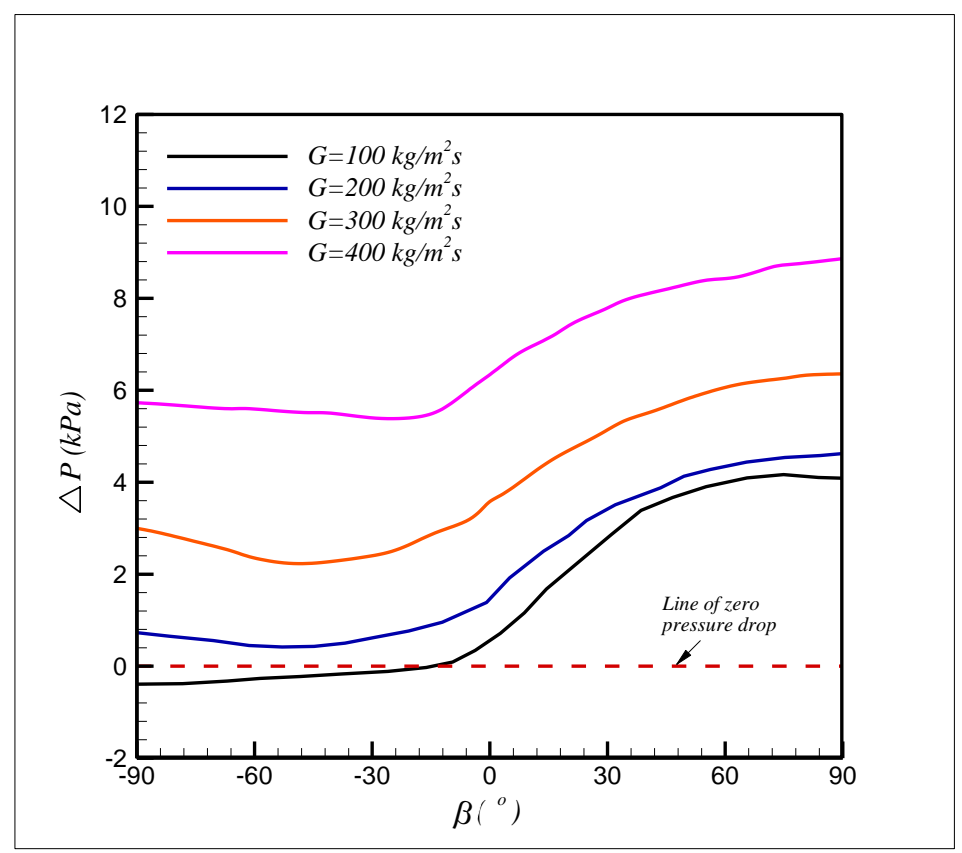

Fig. 5 Numerical results of pressure drops as function of inclination angles and mass fluxes at a quality of $50 \%$. 


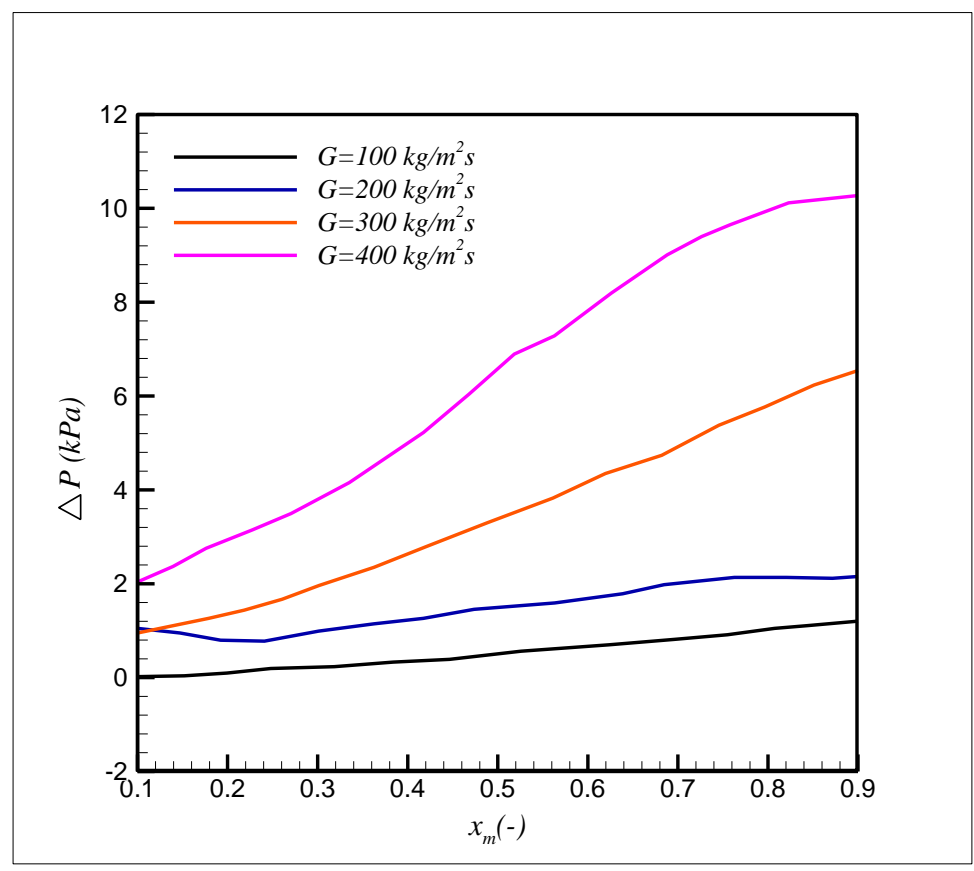

Fig. 6 Simulated pressure drops as function of qualities and mass fluxes along the tube in a horizontal configuration $(\beta=0)$. 
Fig. 7 shows the variation of frictional pressure drop along the tube for different tube orientations and vapour qualities for mass fluxes of $200 \mathrm{~kg} / \mathrm{m}^{2} . \mathrm{s}$ (Fig. 7a), $300 \mathrm{~kg} / \mathrm{m}^{2} . \mathrm{s}$ (Fig. 7b), and $400 \mathrm{~kg} / \mathrm{m}^{2} . \mathrm{s}$ (Fig. 7c). The frictional pressure drops increased with increases in mass fluxes. The highest frictional pressure drops occurred at vertical downward flows, while the lowest frictional pressured drop was generally achieved during upward flow orientations. Furthermore, the plots for each mass flux shows that the vapour qualities had a significant effect on the frictional pressure drops. Higher vapour qualities resulted in higher frictional pressure drops. Also, the effects of tube orientation on the frictional pressure drops decreased with an increase in the vapour qualities. This is due to the fact that the liquid hold-up decreased as the vapour quality increased.

The plots in Figs. 7 also show that there exists a minimum value for the frictional pressure drop at an inclination angle, close to the horizontal orientation, where $\beta \simeq 0^{\circ}$. This occurs specifically at low qualities, of $25 \%$ and $50 \%$.

Fig. 8 shows the variations of wall shear stress along the tube wall at different inclination angles. The results are given for a mass flux of $100 \mathrm{~kg} / \mathrm{m}^{2} . \mathrm{s}$ and a quality of $25 \%$. Fig. $8 \mathrm{a}$ is for a downward inclination angle of $-90^{\circ}$ and the flow pattern was annular, Fig. $8 \mathrm{~b}$ is for a downward inclination angle of $-60^{\circ}$ and the flow pattern was stratified wavy, Fig. $8 \mathrm{c}$ is for flow in a horizontal direction with an inclination angle of $0^{\circ}$, and the flow pattern was stratified, and Fig. $8 \mathrm{~d}$ is for an upward inclination angle of $+60^{\circ}$ and the flow pattern was churn

Fig. 8a shows an almost uniform wall stress for annular flow. It is due to the fact that the liquid film at the wall is uniform and smooth. However in stratified wavy flow shown in Fig. $8 b$, the wall shear stress is oscillating along the tube wall. In Fig. 8c, the wall shear stress is almost smooth for stratified flow, almost like in annular flow but the magnitude of the shear stress is a little bit lower. As the flow pattern changes to churn (Fig. 8d), the wall shear stresses also oscillates, but the frequency along the choose length is more random than for the stratified wavy flow shown in Fig. 8b. 


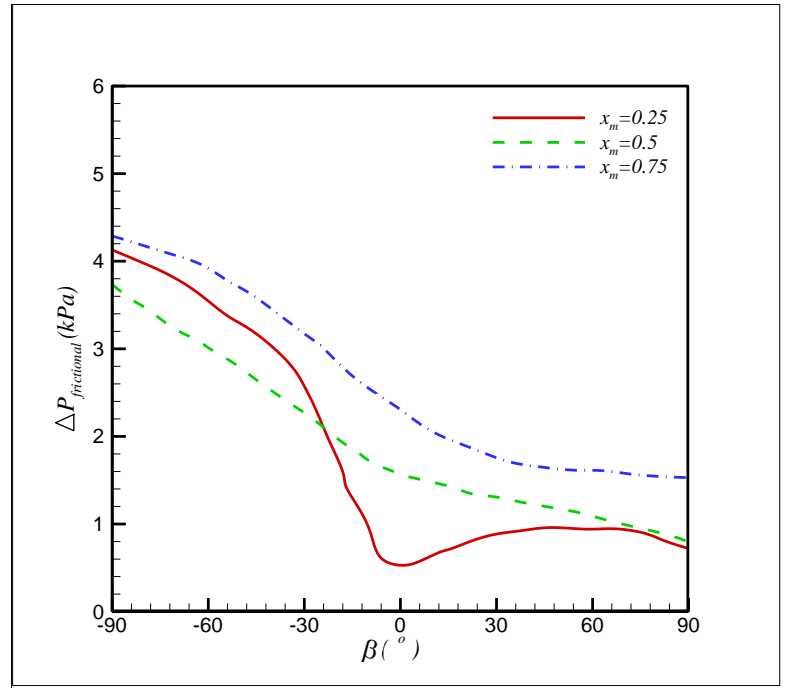

(a)

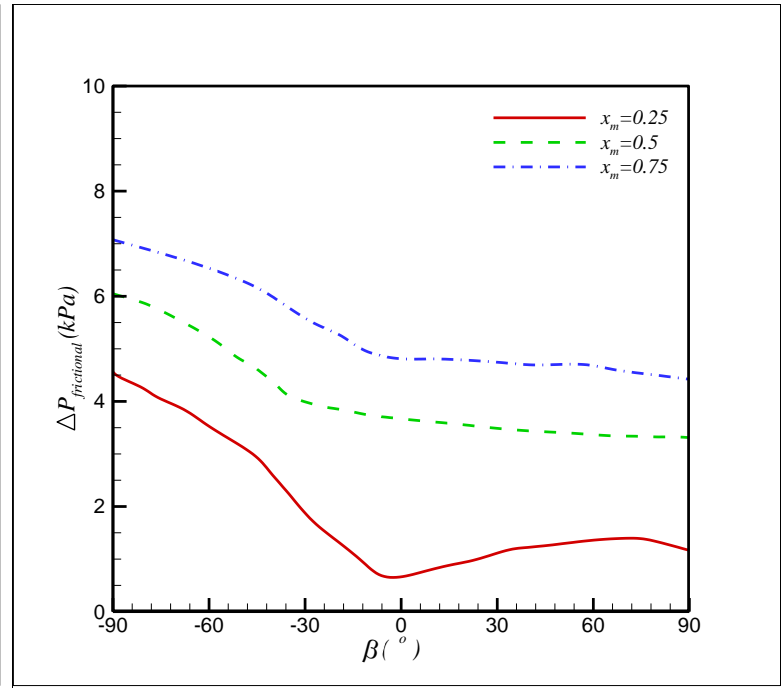

(b)

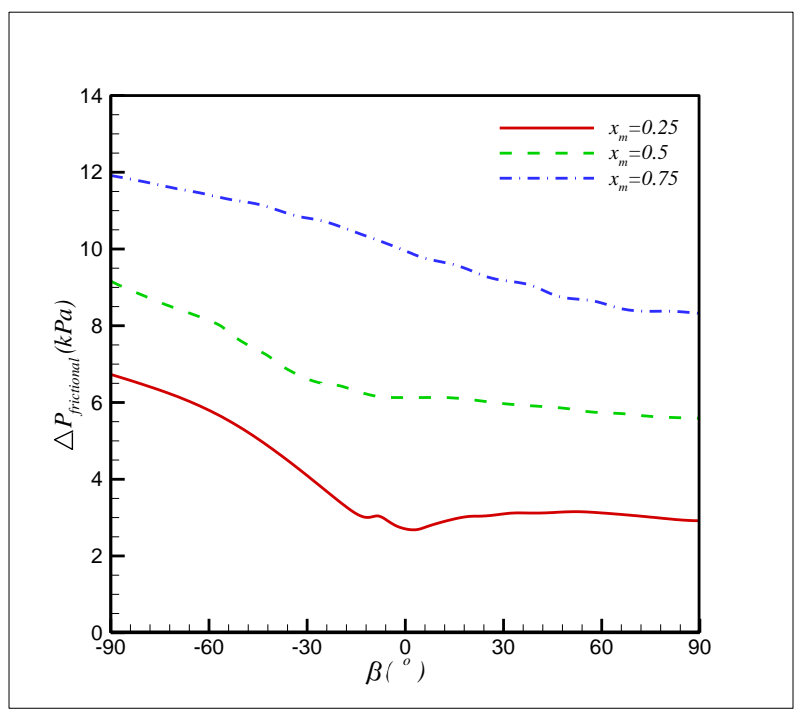

(c)

Fig. 7 Effect of inclination angle on simulated frictional pressure drops for different vapour qualities at mass fluxes of (a) $G=200 \mathrm{~kg} / \mathrm{m}^{2}$ s , (b) $G=300 \mathrm{~kg} / \mathrm{m}^{2} . \mathrm{s}$, and (c) $G=400 \mathrm{~kg} / \mathrm{m}^{2} . \mathrm{s}$. 


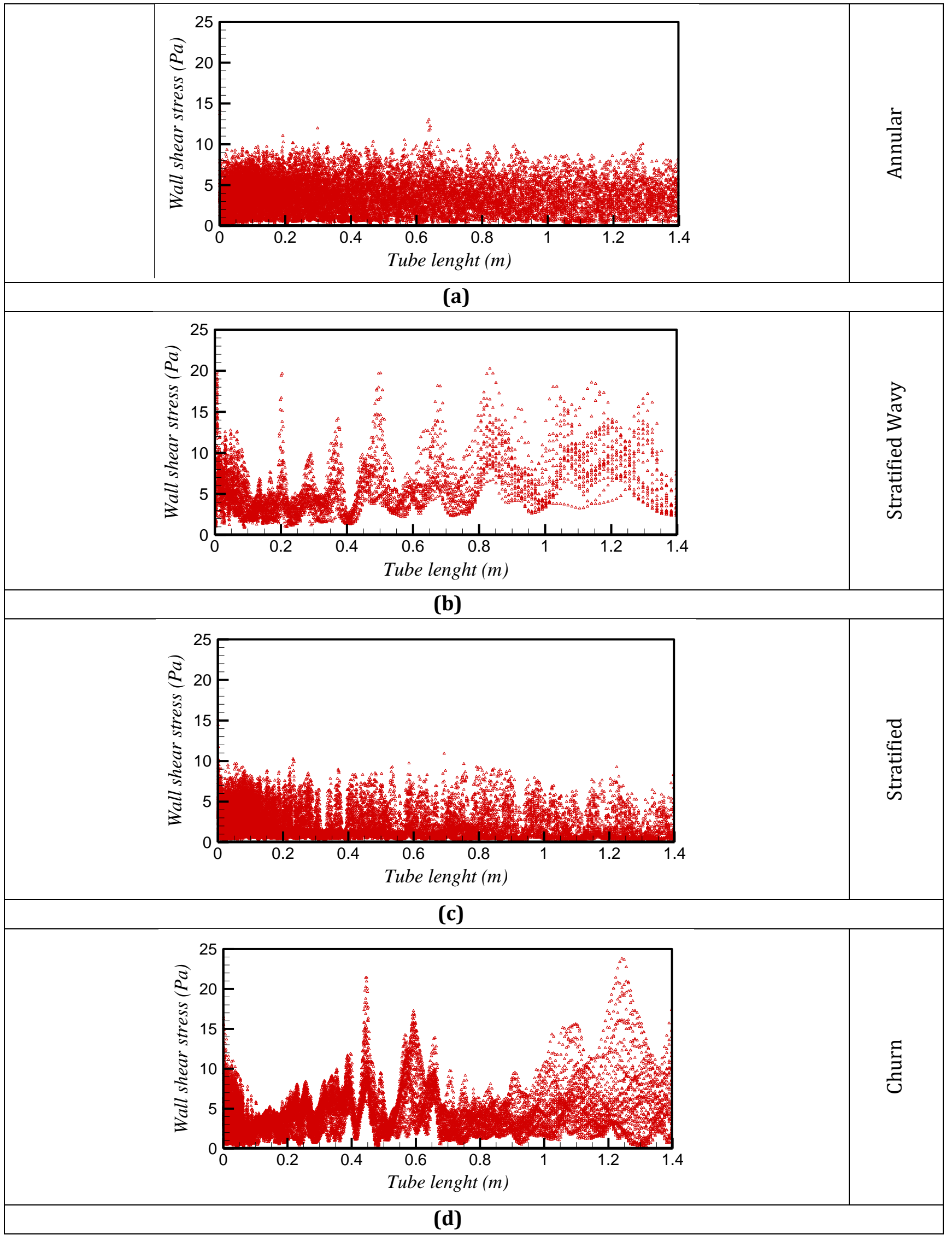

Fig. 8 Variations of wall shear stress along the tube length for a quality of $25 \%$ and a mass flux $100 \mathrm{~kg} / \mathrm{m}^{2} . \mathrm{s}$, for inclination angles of; (a) $\beta=-90^{\circ}$ (annular flow regime), (b) $\beta=-60^{\circ}$ (stratified wavy flow regime), (c) $\beta=0$ (stratified flow regime), and (d) $\beta=60^{\circ}$ (churn flow regime). 


\subsection{Void fractions}

Fig. 9 shows the numerically simulated and measured void fractions by Olivier et al. (2016) and Lips and Meyer (2012c) as function of inclination angles for three different qualities of 25\%, 50\%, and 75\%. The results are also given for mass fluxes of $100 \mathrm{~kg} / \mathrm{m}^{2} . \mathrm{s}$, (Fig. 9a) $200 \mathrm{~kg} / \mathrm{m}^{2}$.s (Fig. 9b), and $300 \mathrm{~kg} / \mathrm{m}^{2}$.s (Fig. 9c). The void fractions are the averages of the void fractions at the inlet and outlet of the test section. In general, the predicted values are in good agreement with experimental data, which proves the capability of the presented numerical method to accurately predict the condensation phenomenon inside inclined smooth tubes during condensation.

For a mass flux of $100 \mathrm{~kg} / \mathrm{m}^{2} . \mathrm{s}$ (Fig. 9a), and for upward flow $\left(\beta>0^{\circ}\right.$ ), the void fraction values for a quality of $25 \%$, decreased significantly. It is due to the fact that at low mass fluxes when the flow direction turned upward the flow regime changed from stratifiedwavy to churn, which decreased the void fractions values. When the qualities increased to $50 \%$, and $75 \%$, the flow regimes remained stratified or stratified-wavy, therefore, the inclination angle had no significant effect on the void fractions.

At a mass flux of $200 \mathrm{~kg} / \mathrm{m}^{2} . \mathrm{s}$ (Fig. 9b), the results compared well with the measurements, however, the results are less dependent on quality as compared to Fig. 9a. Furthermore, effects of the inclination angles on void fractions were less significant. The reason is that as the mass fluxes increases the shear forces increases while the gravity forces remains constant. The flow regimes therefore remains annular or stratified. This tendency of the void fraction becoming independent of inclination angle as the mass flux increased is best illustrated by comparing the void fractions at a mass flux of $300 \mathrm{~kg} / \mathrm{m}^{2} . \mathrm{s}$ (Fig. 9c), with the void fractions at mass fluxes of $200 \mathrm{~kg} / \mathrm{m}^{2} . \mathrm{s}$ (Fig. 9b), and $100 \mathrm{~kg} / \mathrm{m}^{2} . \mathrm{s}$ (Fig. 9a).

The void fraction independence on inclination angle at different mass fluxes also occurred specifically at high qualities. This can be shown by comparing the void fractions at a quality of 75\% in Figs. 9a-c. At a mass flux of $100 \mathrm{~kg} / \mathrm{m}^{2} . \mathrm{s}$ (Fig. 9a), the void fractions at a quality of $75 \%$, varied between a minimum of $94.1 \%$ and a maximum of $97.0 \%$. At the same quality it varied between $92.5 \%$ and $94.8 \%$ for a mass flux of $200 \mathrm{~kg} / \mathrm{m}^{2} . \mathrm{s}$ (Fig. 9b), and between $89.3 \%$ and $93.4 \%$ for a mass flux of $300 \mathrm{~kg} / \mathrm{m}^{2} . \mathrm{s}$ (Fig. 9c). 


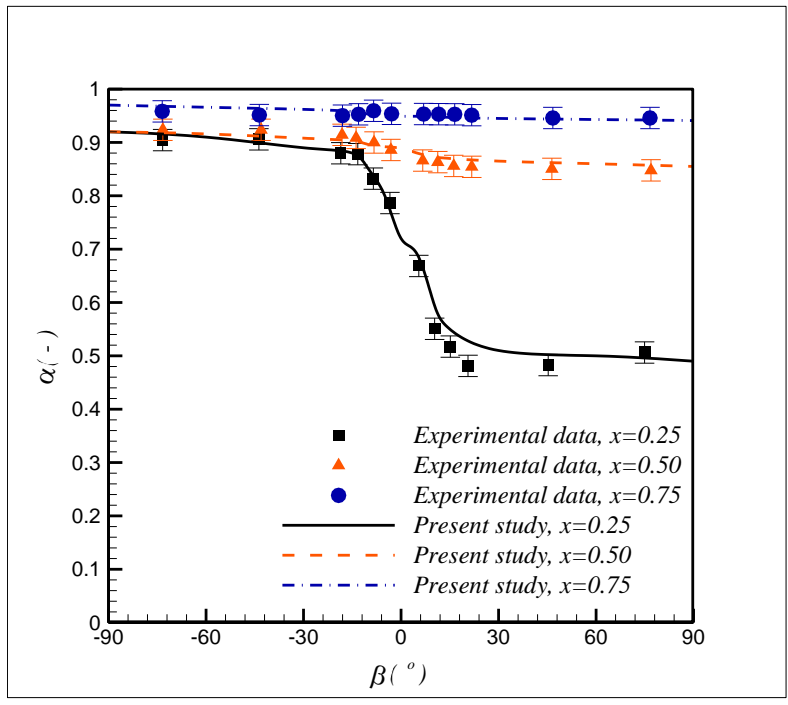

(a)

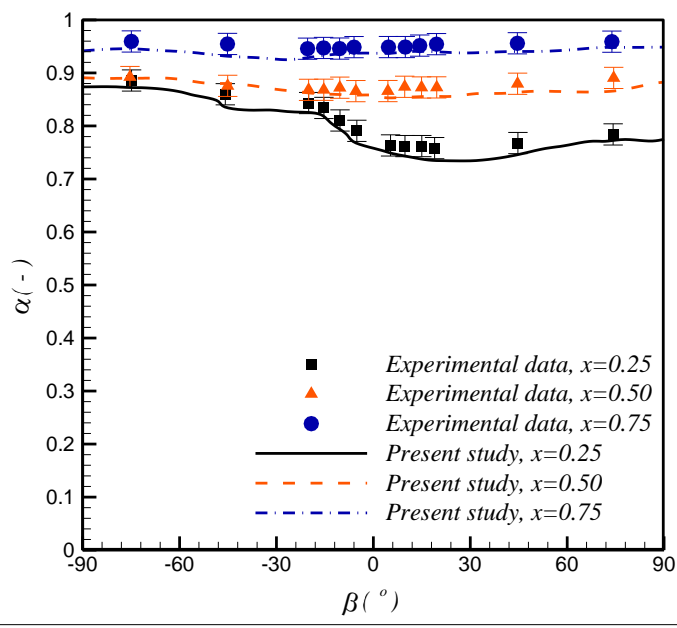

(b)

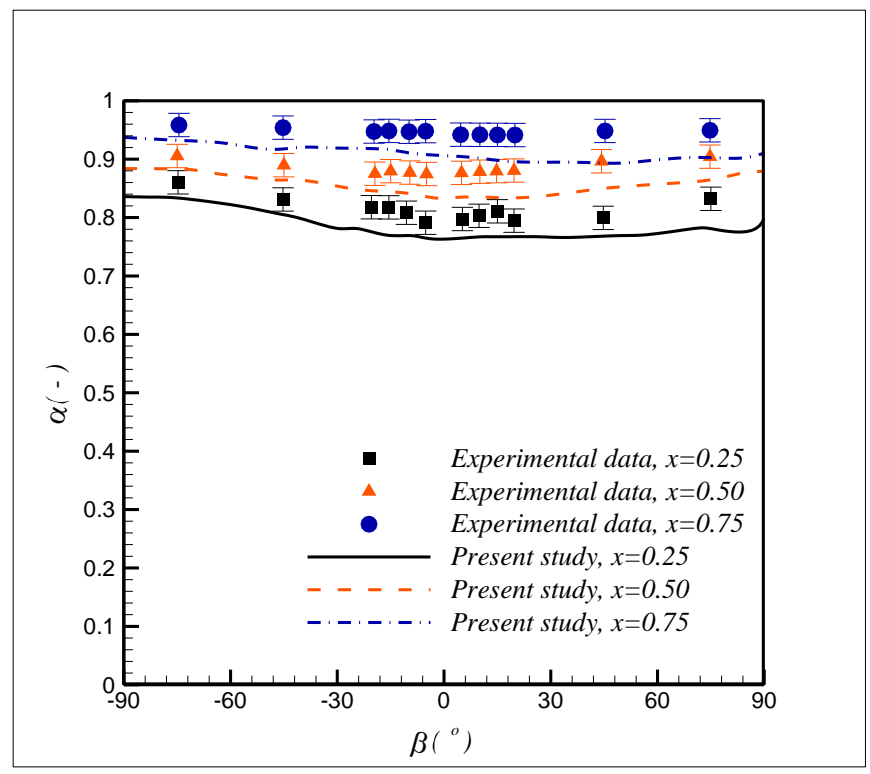

(c)

Fig. 9 Numerically simulated and measured void fractions (Olivier et al., 2016) as function of inclination angles and qualities for mass fluxes of: (a) G $=100 \mathrm{~kg} / \mathrm{m}^{2} . \mathrm{s}$, (b) $\mathrm{G}=200 \mathrm{~kg} / \mathrm{m}^{2} . \mathrm{s}$, and (c) G=300 kg/m $\mathrm{m}^{2} . \mathrm{s}$. 


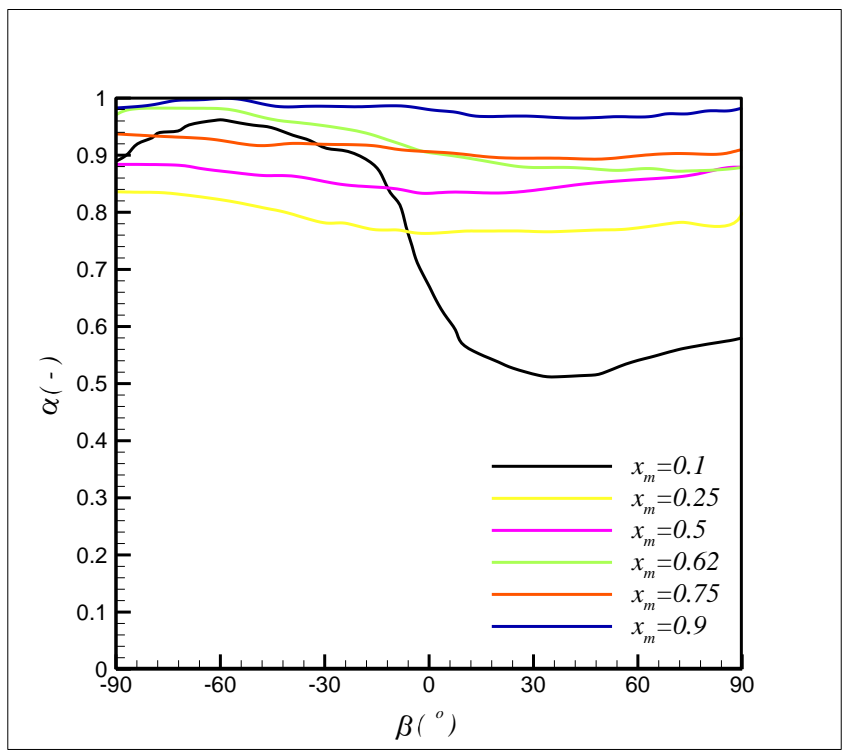

Fig. 10 Void fractions as functions of inclination angles and qualities varying from $10 \%$ to $90 \%$, at a mass flux of $300 \mathrm{~kg} / \mathrm{m}^{2} \cdot \mathrm{s}$. 
Fig. 10 shows the numerically simulated void fractions at a mass flux of $300 \mathrm{~kg} / \mathrm{m}^{2} . \mathrm{s}$, as function of inclination angles for six quality values varying from $10 \%$ to $90 \%$. As was also concluded in Fig. 9, the results showed that the void fraction increased as the quality increased. Furthermore, at low qualities (best illustrated with a quality of $10 \%$ in Fig. 10), the inclination angle effect on void fraction is significant, especially for flow in an upward flow direction $\left(\beta>0^{\circ}\right)$. At low qualities the gravity is the dominant force compared to the shear forces and the change of the inclination angle from downward to upward leads to a change in the flow regime to churn flow. In the downward direction at low qualities the flow regimes were predominantly annular or stratified, while in the upward direction it was predominately churn.

\subsection{Flow regimes}

Fig. 11 shows the contours of volume fraction at a mass flux of $100 \mathrm{~kg} / \mathrm{m}^{2} . s$ and quality of $75 \%$. In this figure the volume fractions are presented at seven different inclination angles from vertical downward $\left(\beta=-90^{\circ}\right)$ to vertical upward flow $\left(\beta=+90^{\circ}\right)$. In the figure blue represents a volume fraction of a saturated vapour and red represents a volume fraction of saturated liquid.

As discussed previously, at high vapour qualities the flow regime was almost annular particularly for vertical tube orientations $\beta=-90^{\circ}$ (Fig. 11a) and $\beta=+90^{\circ}$ (Fig. 11g). When the inclination angle changed from $\beta=-90^{\circ}$ to the horizontal direction, the flow regime changed to stratified or stratified/wavy due to the effect of gravity (Figs. $11 \mathrm{~b}$-d). With further change of the inclination angle from the horizontal to the upward direction, the liquid film on the bottom side of the tube became a bit unstable due to opposite direction of the gravity force toward the flow direction (Figs. 11e and f). It is worth noting that the changes in flow regimes were not significant due to existence of the high vapour quality.

Therefore, since no significant changes in the flow regime occurred during these wide range of inclination angles, the heat transfer coefficients and pressure drops also did not change significantly at these inclination angles.

More captured flow regimes and detailed explanations can be found in Noori Rahim Abadi et al., (2017). 


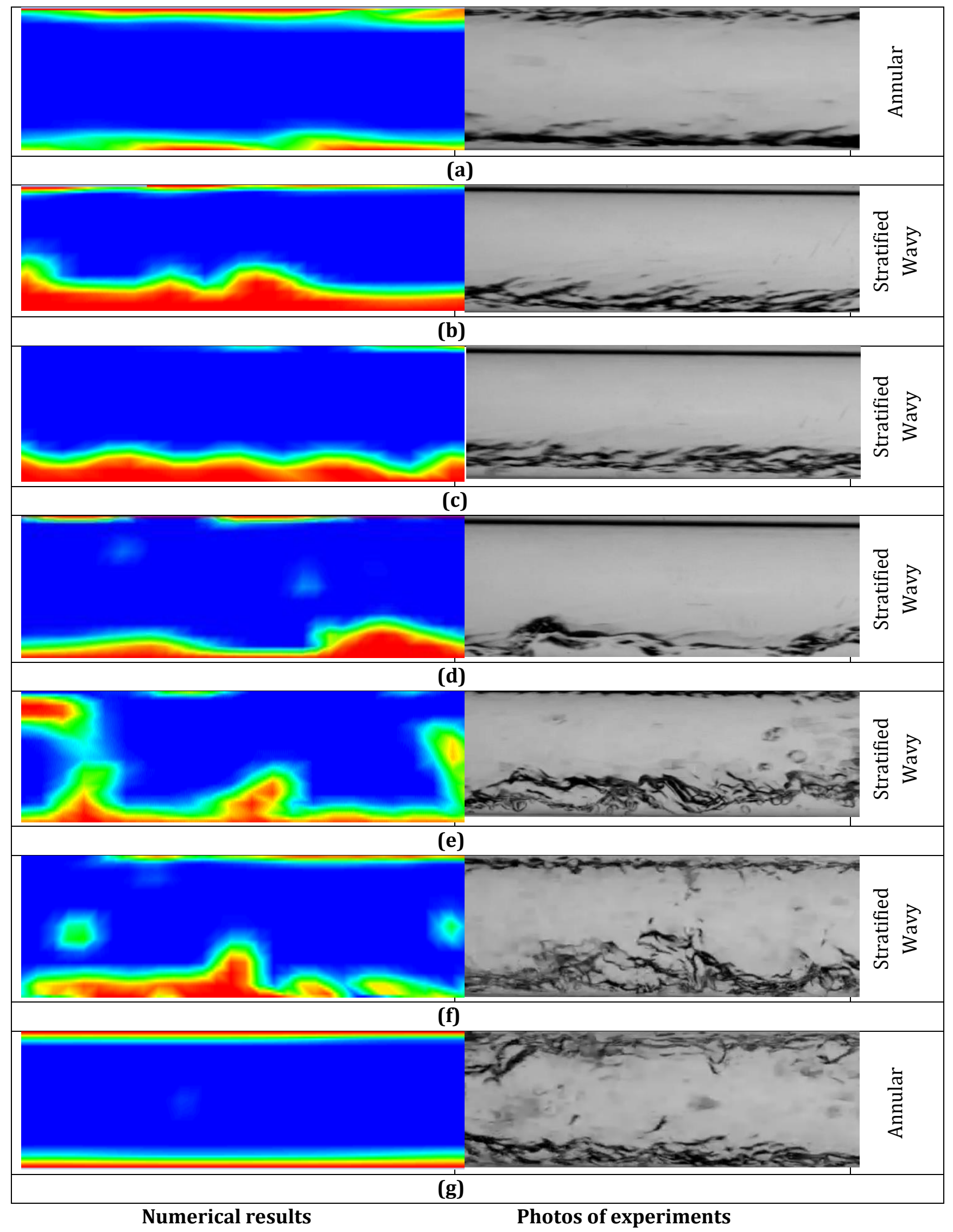

Fig. 11 Volume fraction contours and experimental photographs of Lips and Meyer (2012b), at a quality of 75\% and a mass flux of $100 \mathrm{~kg} / \mathrm{m}^{2} . \mathrm{s}$, at different inclination angles of: (a) $\theta=-90^{\circ}$, (b) $\theta=-60^{\circ}$, (c) $\theta=-30^{\circ}$, (d) $\theta=0^{\circ}$, (e) $\theta=+30^{\circ}$, (f) $\theta=+60^{\circ}$, and (g) $\theta=+90^{\circ}$. 


\section{Conclusions}

In this paper the effects of inclination angles during condensation on pressure drops and void fractions were investigated numerically and the results were compared to experiments. The governing equations solved used the VOF multiphase-flow method and the numerical solver used was ANSYS FLUENT 17.1. The flow field was assumed to be unsteady, turbulent and three-dimensional. The fluid properties were considered to be constant as temperature changes were assumed to be negligible.

It was found that the effect of inclination angle on pressure drop and void fraction became negligible at high mass fluxes and vapour qualities. The pressure drop increased as the void fraction increased. The pressure drops also increased when the mass fluxes increased. These increases were more significant at high vapour qualities. Furthermore, at low qualities or mass fluxes, changes in flow directions from downward to upward resulted in flow regime changes from annular or stratified wavy to churn. This resulted in a decrease in void fractions and an increase in pressure drops.

\section{Nomenclature}

E Internal energy, J

$F \quad$ Source term in the momentum equation, $\mathrm{N} \cdot \mathrm{m}^{-3}$

$g$ Gravitational acceleration, $\mathrm{m} \cdot \mathrm{s}^{-2}$

$h \quad$ Heat transfer coefficient, W.m-2.K

$G_{b} \quad$ Generation of turbulence kinetic energy due to buoyancy, $\mathrm{m}^{4} . \mathrm{s}^{-1}$

$k \quad$ Thermal Conductivity, W.m-2.K

$p \quad$ Pressure, $\mathrm{Pa}$

$q$ " Heat flux, W.m-2

$R \quad$ Tuning coefficient, $\mathrm{s}^{-1}$

Ma Mach number

$S_{E} \quad$ Energy source term, J.m ${ }^{-3}$.S

$S_{l} \quad$ Condensation mass source term, kg.m ${ }^{-3} . \mathrm{s}$

$S_{v} \quad$ Evaporation mass source term, kg.m-3.s

$t$ Time, $\mathrm{s}$

$T$ Temperature, $\mathrm{K}$ 
$\vec{u} \quad$ Velocity, $\mathrm{m} \cdot \mathrm{s}^{-1}$

$x \quad$ Vapour quality

\section{Greek symbols}

$\mu \quad$ Molecular viscosity, Pa.s

$\rho \quad$ Density, kg.m ${ }^{-3}$

$k \quad$ Turbulent kinetic energy, $\mathrm{m}^{-2} \cdot \mathrm{s}^{-2}$

$\varepsilon \quad$ Turbulent dissipation rate, $\mathrm{m}^{-2} \cdot \mathrm{s}^{-3}$

$\beta \quad$ Inclination angle, degree

$\alpha \quad$ Volume fraction

\section{Subscripts}

$\begin{array}{ll}\text { ave } & \text { Average } \\ \text { eff } & \text { Effective } \\ l & \text { Liquid } \\ L & \text { Laminar } \\ m & \text { Mixture } \\ \text { sat } & \text { Saturation } \\ t & \text { Turbulent } \\ v & \text { Vapour } \\ \text { wall } & \text { Tube wall }\end{array}$

\section{References}

Azizi, S., Ahmadloo, E., 2016. Prediction of heat transfer coefficient during condensation of R134a in inclined tubes using artificial neural network. App. Therm. Eng. 106, 203210.

Beggs, D. H., Brill, J. P., 1973. A study of two-phase flow in inclined pipes. J. Pet. Technol. 25.

Behafarid, F., Jansen, K. E., Podowski, M. Z., 2015. A study on large bubble motion and liquid film in vertical pipes and inclined narrow channels. Int. J. Multi. Flow 75, 288299.

Brackbill, J. U., Kothe, D. B., Zemach, C., 1992. A continuum method for modeling surface tension. Comput. Phys. 100, 335-354.

Caruso, G., Giannetti, F., Naviglio, A., 2012. Experimental investigation on pure steam and steam-air mixture condensation inside tubes. Int. J. Heat Technol. 30, 77-84. 
Caruso, G., Maio, D. V., Naviglio, A., 2013a. Film condensation in inclined tubes with noncondensable gases: an experimental study on the local heat transfer coefficient. Int. Commun. Heat Mass Transf. 45, 1-10.

Caruso, G., Maio, D. V., Naviglio, A., 2013b. Condensation heat transfer coefficient with non-condensable gases inside near horizontal tubes, Desalination 309, 247-253.

Caruso, G., Maio, D. V., 2014. Heat and mass transfer analogy applied to condensation in the presence of non-condensable gases inside inclined tubes. Int. J. Heat Mass Transf. $68,401-414$.

Chato, J. C., 1962. Laminar condensation inside horizontal and inclined tubes, American Society Heating Refrigerating Air Conditioning Engineering (ASHRAE) 4, 52-60.

Del Col, D., Bortolato, M., Azzolin, M., Bortolin, S., 2014. Effect of inclination during condensation inside a square cross section mini channel. Int. J. Heat Mass Transf. 78, 760-777.

Dziubinski, M., 1995. General correlation for two-phase pressure drop in intermittent flow of gas and non-Newtonian liquid mixtures in a pipe. Chem. Eng. Res. Des. 73, 528534.

Fair, J. 1960. What you need to design thermo-siphon reboilers. Petroleum Refiner 39, pp. 105-123.

Fu, W., Li, X., Wu, X., Corradini, M. L., 2016. Numerical investigation of convective condensation with the presence of non-condensable gases in a vertical tube. Nuc. Eng. Des. 297, 197-207.

Hirt, C. W., Nichols, B. D., 1981. Volume of fluid (VOF) method for the dynamics of free boundaries. J. Comput. Physics 39, 201-225.

Lee, W. H., 1979. A pressure iteration scheme for two-phase modeling. Technical Report LA-UR 79-975, Los Alamos Scientific Laboratory, Los Alamos, New México.

Lee, W. H., 1980. A Pressure Iteration Scheme for Two-Phase Flow Modeling, Multiphase Transport: Fundamentals, Reactor Safety, Applications, Verizoglu, T. N., ed., Hemisphere Publishing, Washington, DC.

Liebenberg, L., Meyer, J.P., 2008a. Refrigerant condensation flow regimes in enhanced tubes and their effect on heat transfer coefficients and pressure drops. Heat Transf. Eng. 29, 506-520. 
Liebenberg, L., Meyer, J.P., 2008b. A review of flow pattern-based predictive correlations during refrigerant condensation in horizontally smooth and enhanced tubes. Heat Transf. Eng. 29, 3-19.

Li, J., 2013. CFD simulation of water vapour condensation in the presence of noncondensable gas in vertical cylindrical condensers. Int. J. Heat Mass Transf. 57, 708721.

Lin, C., Wang, D., Bao, A., 2013. Numerical modeling and simulation of condensation heat transfer of a flue gas in a bundle of transport membrane tubes. Int. J. Heat Mass Transf. $60,41-50$.

Lips, S., Meyer, J. P., 2011. Two-phase flow in inclined tubes with specific reference to condensation: A review. Int. J. Multi. Flow 37, 845-859.

Lips, S., Meyer, J.P., 2012a. Stratified flow model for convective condensation in an inclined tube. Int. J. Heat Fluid Flow 36, 83-91.

Lips, S., Meyer, J.P., 2012b. Experimental study of convective condensation in an inclined smooth tube. Part I: Inclination effect on flow pattern and heat transfer coefficient. Int. J. Heat Mass transf. 55, 395-404.

Lips, S., Meyer, J.P., 2012c. Experimental study of convective condensation in an inclined smooth tube. Part II: Inclination effect on pressure drops and void fractions. Int. J. Heat Mass transf. 55, 405-412.

Lips, S., Meyer, J.P., 2012d. Effect of gravity forces on heat transfer and pressure drop during condensation of R134a. Microgravity Sci. Technol. 24, 157-164.

Liu, Z., Sunden, B., Yuan, J., 2012. VOF modeling and analysis of film wise condensation between vertical parallel plates. Heat Transf. Res. 43, 47-68.

Lizarraga-Garcia, E., Buongiorno, J., Bucci, M., 2016. An analytical film drainage model and breakup criterion for Taylor bubbles in slug flow in inclined round pipes. Int. J. Multi. Flow 84, 46-53.

Meyer, J. P., Dirker, J., Adelaja, A. O., 2014. Condensation heat transfer in smooth inclined tubes for R134a at different saturation temperatures. Int. J. Heat Mass Transf. 70, 515525.

Ndinisa, N.V., Wiley, D.E., Fletcher, D.F., 2005. Computational fluid dynamics simulations of Taylor bubbles in tubular membranes model validation and application to laminar flow systems. Chem. Eng. Res. Des. 83, 40-49. 
Noori Rahim Abadi, S. M. A., Meyer, J. P., Dirker, J., 2017. Numerical investigation of condensation inside an inclined smooth tube, Proc. 13th Int. Conf. Heat Transfer, Fluid Mechanics and Thermodynamics, Portoroz, Slovenia, 576-572.

Olivier, S. P., Meyer, J. P., Paepe, M. D., Kerpel, K. D., 2016. The influence of inclination angle on void fraction and heat transfer during condensation inside a smooth tube. Int. J. Multi. Flow 80, 1-14.

Ratkovich, N., Majumder, S.K., Bentzen, T.R., 2013. Empirical correlations and CFD simulations of vertical two-phase gas-liquid (Newtonian and non-Newtonian) slug flow compared against experimental data of void fraction. Chem. Eng. Res. Des. 9, 988-998

Rudman, M., 1997. Volume-tracking methods for interfacial flow calculations. Int. J. Num. Methods Fluids 24, 671-691.

Städtke, H., 2006. Gasdynamic Aspects of Two-Phase Flow, WILEY-VCH Verlag GmbH \& Co. KGaA.

Szijártó, R., Freixa, J., Prasser, H. M., 2014. Simulation of condensation in a closed slightly inclined horizontal pipe with a modified RELAP5 code. Nuc. Eng. Des. 273, 288-297.

Vadgama, B., Harris, D. K., 2007. Measurements of the contact angle between R134a and both aluminium and copper surfaces. Exp. Therm. Fluid Sci. 31, 979-984.

Xing, F., Xu, J., Xie, J., Liu, H., Wang, Z., Ma, X., 2015. Froude number dominates condensation heat transfer of R245fa in tubes: Effect of inclination angles. Int. J. Multi. Flow 71, 98-115.

Yang, Z., Shih, T. H., 1993. New time scale based $k-\varepsilon$ model for near wall turbulence. AIAA J. 317, 1191-1197. 